\title{
IMPROVEMENT OF ORGANIC RED PIGMENT PRODCUTION BY MONASCUS PURPUREUS TISTR3651 USING PATHUMTHANI-1 RICE-BASED MEDIUM IN SUBMERGED AND SOLID-STATE FERMENTATION
}

\author{
SURACHAI TECHAOEI, KHEMJIRA JARMKOM, THISAKORN DUMRONGPHUTTIDACHA, WARACHATE KHOBJAI
}

Thai Traditional Medicine College, Rajamangala University of Technology Thanyaburi, Prachatiphat, Thanyaburi, Pathumthani, Thailand. Email: surachai_te@rmutt.ac.th

Received: 19 August 2020, Revised and Accepted: 28 September 2020

\section{ABSTRACT}

Objective: This research is to study the production of natural red pigment by Monascus purpureus TISTR3615 in the submerged and solid-state fermentation system using Pathumthani-1 rice as a carbon source.

Methods: The antioxidant activity of the red pigment was evaluated in vitro 2,2-diphenyl-1-picrylhydrazyl (DPPH), ABTS radical scavenging assay, and ferric-reducing antioxidant power (FRAP) assay, including total phenolic compound.

Results and Discussion: The maximum of red pigment production was $0.55 \pm 0.02 / \mathrm{ml}(\mathrm{OD} 680 \mathrm{~nm})$ after incubation at $30^{\circ} \mathrm{C}$ for 24 days. The antioxidant activity based on inhibition DPPH (\%), ABTS radical scavenging activity (\%), and FRAP activity (mM Fe2+/g) was 97.80 \pm 1.51 , $68.64 \pm 0.46$, and $0.32 \pm 0.021$, respectively. The total phenolic content was $164.78 \pm 2.82 \mu \mathrm{g} \mathrm{GAE} / \mathrm{mg}$.

Conclusion: It was estimated that Monascus pigments, leading to nutraceutical and pharmaceutical applications, cosmetic industry, and food industry.

Keywords: Natural pigment, Monascus purpureus, Submerged fermentation, Solid-state fermentation, Agricultural product

(C) 2021 The Authors. Published by Innovare Academic Sciences Pvt Ltd. This is an open access article under the CC BY license (http://creativecommons. org/ licenses/by/4.0/) DOI: http://dx.doi.org/10.22159/ijap.2021.v13s1.Y0103. Journal homepage: https://innovareacademics.in/journals/index.php/ijap

\section{INTRODUCTION}

Pigments production from micro-organisms was used as a probable alternative to synthetic pigments such as synthetic food colors, some of which have a risk to consumer health and may be carcinogenic substance to humans [1]. The previous studies have been reported the natural pigments extracted from plants, animals such as annatto, grapes, beet, paprika, female insects (Coccus cacti), and micro-organisms such as Monascus, Rhodotorula, Bacillus, Achromobacter, Phaffia, and Streptomyces [2,3]. This study is a growing interest in microbial pigments due to their natural compounds providing the potential for safe uses to human health, including medicinal properties such as antibacterial and anti-cancer activities, nutritional effects controllable, and predictable yield [1].

Red mold rice (RMR) or Monascus purpureus is one of the richest producers of various pigments which reported to have a complex mixture of six chemically colored compounds of polyketide source [4]. These compounds contain a many sources of yellow-red pigment such as rubropunctatine, monascorubrine (orange), rubropunctamine, monascorubramine (red), monascine, and ankaflavine (yellow) [1,5]. In addition, M. purpureus are used in the production of pigment using rice, corn or cassava, oat, wheat, barley, tofu, and meat as a substrate [1,6]. Interestingly, Fabre et al. [7] reported that pigments from Monascus have potent therapeutic treatment. Lin et al. [8] found that red pigments indicated anti-bacterial property against Bacillus subtilis, Bacillus megaterium, Escherichia coli, and Pseudomonas aeriginosa. Moreover, monacolin K is an important bioactive compound from Monascus, which is responsible to the potent cholesterol-lowering, anti-atherosclerotic drug lovastatin, a 3-hydroxy-3-methylglutaryl coenzyme A (HMG-CoA) reductase inhibitor $[9,10]$.

The cheap agricultural products and biomass residues, which are abundant in agricultural countries in the world, including Thailand, are an important sources for both energy utilization and novel product improvement. They will become the key to reducing the sustainable agricultural production system in the future. Hence, the objective of this study was focused the production of natural red pigment by $M$. purpureus TISTR3615 in the submerged and solid-state fermentation system using Pathumthani-1 rice as a carbon source. The antioxidant activity of the red pigment was evaluated in vitro 2,2-diphenyl-1picrylhydrazyl (DPPH), ABTS radical scavenging assay, and ferric reducing antioxidant power (FRAP) assay, including total phenolic compound.

\section{METHODS}

Micro-organism and medium cultivation

M. purpureus TISTR3615 strain was obtained from the Thailand Institute of Scientific and Technological Research. The eight culture strains were maintained on a potato dextrose agar plate at $30^{\circ} \mathrm{C}$ for 10 days and followed by storage at $4^{\circ} \mathrm{C}$.

\section{RMR preparation by solid-state fermentation}

The Pathumthani-1 rice was obtained from Pathum Thani Rice Research Center, Pathum Thani, Thailand, used as a raw material for RMR production. Fifty grams of rice were soaked in $50 \mathrm{~mL}$ of distilled water. Then, the soaked rice was autoclaved for $20 \mathrm{~min}$ at $121^{\circ} \mathrm{C}$ in polyethylene bag with put-on a bottleneck and cotton. After it was cooled, five pieces of each M. purpureus TISTR3615 were added with dimensions of $0.6 \mathrm{~cm}^{2}$ by Cork Borer and cultivated at $30^{\circ} \mathrm{C}$ for 20 days. After the end of the cultivation, the RMR was dried at $50^{\circ} \mathrm{C}$ for 2 days and crushed into powder.

Production of red pigment by M. purpureus TISTR3615 under submerged fermentation

M. purpureus TISTR3615 was cultivated into a $250 \mathrm{~mL}$ Erlenmeyer flask containing $100 \mathrm{~mL}$ of Yeast Malt Broth medium (YM Broth). These cultured samples were incubated at $30^{\circ} \mathrm{C}$ for 24 days. After that, the production of pigment in the cultured medium was filtrated with Whatman filter paper and measured using a UV spectrophotometer at a wavelength of $680 \mathrm{~nm}$. In this experiment, YM broth was used as a blank for the detection of pigment in cultured broth medium.

Extraction of red pigment of M. purpureus TISTR3615

The 5 gm of fermented product were taken for pigment extraction as describe by Rajasekaran and Kalaivani et al. [10] and then filtrated through Whatman filter paper number 1 . The filtrated was vaporized 
by rotary evaporator at $45^{\circ} \mathrm{C}$ and kept in dark bottle at $4{ }^{\circ} \mathrm{C}$ until further study.

\section{Antioxidant activity by 1,1-diphenyl-2-picryl-hydrazyl radical scavenging activity}

Antioxidant activity of all RMR samples was evaluated using the DPPH assay. First, $20 \mu \mathrm{L}$ of RMR powder diluted appropriately in DMSO at the concentration of $0,20,40,60,80,100,200$, and $400 \mu \mathrm{g} / \mathrm{mL}$ were mixed with $180 \mu \mathrm{L}$ of DPPH in methanol $(40 \mathrm{mg} / / \mathrm{mL})$ in wells of 96 -well plate. Next, the plate was kept in a dark room for $30 \mathrm{~min}$ at room temperature. After, the absorbance of the sample was measured at $517 \mathrm{~nm}$ using a spectrophotometer microplate reader. Free-radical scavenging activity of RMR was determined as the percentage of reduced DPPH and was calculated following the equation (1)

Inhibition of DPPH $(\%)=[($ Ac-As $) / A c] \times 100$

When Ac is absorbance of control ( $20 \mu \mathrm{L}$ of DMSO instead of sample) and as is absorbance of the sample. For this DPPH assay, ascorbic acid and DMSO were used as a positive and negative control, respectively [11].

\section{Total phenolic content assay}

The total phenolic content of each RMR powder sample was determined by reaction with Folin-ciocalteu reagent (F-C reagent). Ten microliters of RMR powder diluted in DMSO were mixed with $100 \mu \mathrm{L} \mathrm{F-C} \mathrm{reagent}$ freshly diluted a ratio of F-C reagent per distilled water as $1: 10 \mathrm{v} / \mathrm{v}$. After $5 \mathrm{~min}$, the solution was mixed with $100 \mu \mathrm{L}$ of $7.5 \% \mathrm{Na}_{2} \mathrm{CO}_{3}$ solution and incubated in the dark at room temperature for $60 \mathrm{~min}$. After incubation, the absorbance of the solution was detected by a microplate reader at $765 \mathrm{~nm}$. The TPC measurements were presented as a microgram of Gallic acid equivalents per milligram of RMR sample ( $\mu \mathrm{g} \mathrm{GAE} / \mathrm{mg}$ ) according to a Gallic acid standard curve [12].

\section{ABTS radical scavenging assay}

First, the ABTS stock solution was prepared by mixing an equal concentration of $7 \mathrm{mM}$, which contains an ABTS with $2.45 \mathrm{mM}$ of potassium persulfate aqueous solutions and incubating the same for 12$16 \mathrm{~h}$ under dark condition. Next, the ABTS stock solution was diluted with methanol to obtain an absorbance value of $0.706 \pm 0.02$ at $734 \mathrm{~nm}$. After the addition of $20 \mu \mathrm{L}$ of RMR extract sample to $180 \mu \mathrm{L}$ of diluted ABTS solution, the absorbance was measured at $30 \mathrm{~min}$ after the initial mixing. Percent inhibition of absorbance was calculated using the formula,

ABTS radical scavenging $(\%)=((\mathrm{AB}-\mathrm{AA}) / \mathrm{AB}) \times 100$

Where $\mathrm{AB}$ is absorbance of ABTS radical + methanol and AA is absorbance of ABTS radical + sample extract/standard. This experiment uses ascorbic acid as the standard substrate [13].

\section{FRAP assay}

This assay was perform by mixing $20 \mu \mathrm{L}$ of RMR extract sample $(10 \mathrm{mg} / \mathrm{mL})$, and Ferrous sulfate $\left(\mathrm{FeSO}_{4}\right)(0-1.2 \mathrm{mM})$ as a standard, with $180 \mu \mathrm{L}$ of FRAP reagent. The mixture was incubated for $6 \mathrm{~min}$ at $37^{\circ} \mathrm{C}$, and the absorbance was measured at $595 \mathrm{~nm}$. The FRAP reagent was made by mixing the following three different solutions; $10 \mathrm{mM}$ of 2,4,6-tri(2-pyridyl)-1,3,5-triazine (TPTZ), $300 \mathrm{mM}$ of acetate buffer ( $\mathrm{pH}$ 3.6), and $20 \mathrm{mM}$ of FeCl3 at 1:10:1 ratio, which is mixed before use in the assay. FRAP activity was calculated as ferrous equivalents [14].

\section{Chemical analysis using GC-MS analysis}

The chemical compounds were determined by the method of Valgas et al. [15]. Crude extracts composition analysis was performed on an Agilent 7890 GC system instrument equipped with HP-5MS (5\% diphenyl and $95 \%$ dimethylpolysiloxane) column ( $30 \mathrm{~m} \times 0.25 \mathrm{~mm}, 0.25 \mu \mathrm{m})$ and interfaced to a 5975C inert XL MSD with Triple-Axis Detector. An injection volume of $2 \mu \mathrm{L}$ was conducted (split ration of 10:1) injector temperature $250^{\circ} \mathrm{C}$. The column temperature was increased from $60^{\circ}$ to $250^{\circ} \mathrm{C}$ in a rate $5^{\circ} \mathrm{C} / \mathrm{min}$. The outlet temperature was $280^{\circ} \mathrm{C}$. Mass spectra were taken at $70 \mathrm{Da}$. Ms transfer line temperature $250^{\circ} \mathrm{C}$. The components of the extract were identified by comparison of fragmentation patterns in mass spectra with those stored on the spectrometer database and expressed in the literature. The relative percentage of individual components was calculated from the GC peak areas.

\section{RESULTS AND DISCUSSION}

Production red pigment of $M$. purpureus TISTR3615 by submerged fermentation

The fungal strain, M. purpureus TISTR3615, was cultivated on PDB for red pigment production. After incubation times, maximum values of all fungal growth and pigment production was increased by increasing the incubation periods to $8 \mathrm{~h}, M$. purpureus TISTR3615 showed the red pigment (OD $0.55 \pm 0.02 / \mathrm{ml}$ ) (Fig. 1). Results indicated that the level of glucose found on the medium promoted the mycelial growth and that was an important key for pigment production.

Production red pigment of $M$. purpureus TISTR3615 by solid-state fermentation

The agricultural products are wildly used as an alternative to apply in biological processes for high value-added products, including rice, soybean, and corn meal which were selected to reduce their waste management [15]. M. purpureus TISTR3615 strains can produce red pigment. Results showed that the fungal strains displayed more red color when compared with other fungal strain on solid-state fermentation which used Pathum Thani-1 rice as solid-substrate after incubation at $30^{\circ} \mathrm{C}$ for 10 days (Fig. 2). This result agreed with previous data of Chairote et al. [16] who used the Thai glutinous rice as solid-state fermentation for red pigment production. Moreover, the red pigment production of M. purpureus TISTR3615 depended on carbon sauces, nitrogen sources, trace element concentration, vitamin, and environmental cultivation to increasing the mycelial growth and pigment production, including oxygen and surface for attachment of fungal hyphae [17].

Antioxidant activity of $M$. purpureus TISTR3615 under solid-state fermentation using Pathumthani-1 rice as a carbon source The antioxidant activity of red mold pigment from M. purpureus TISTR3615 using Pathumthani rice1 as solid substrate fermentation was analyzed by different in vitro assay and represented in Table 1 . The inhibition of DPPH-scavenging activities, ABTS activity, and FRAP value of red mold pigment of $M$. purpureus TISTR3615 was $97.80 \pm 1.51 \%$, $68.64 \pm 0.46 \%$, and $0.32 \pm 0.021 \mathrm{mMFe}^{2+} / \mathrm{g}$, respectively. The antioxidant activity levels of red mold pigment in this study are comparable to those extracts of Monascus-fermented with rice and brown rice [18], M. purpureus-fermented rice, corn, and sorghum [19], Monascus-durian seed [20] M. purpureus-purple rice [21].

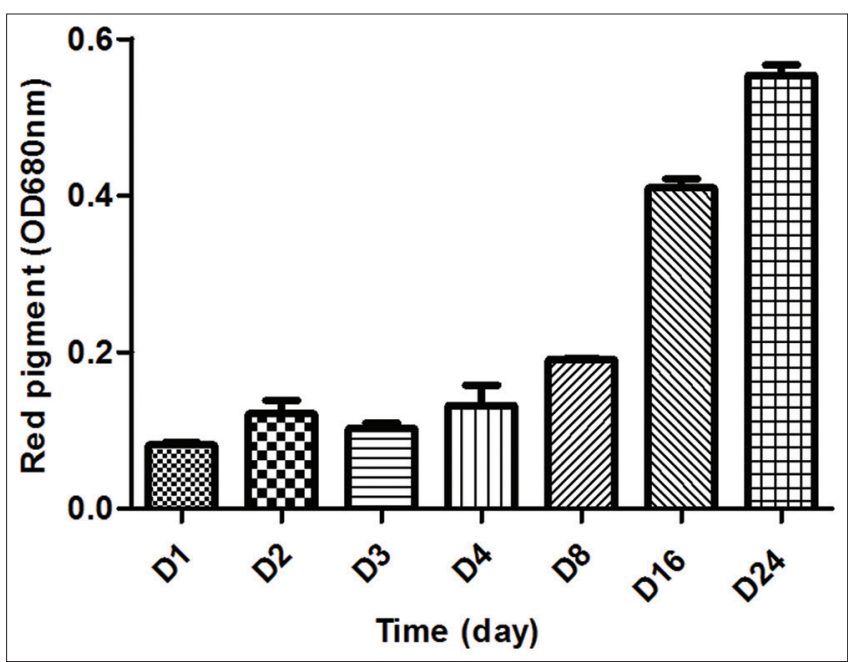

Fig. 1: The production of red pigment of Monascus purpureus TISTR3615 under submerged fermentation was observed for 24 days after fermentation 

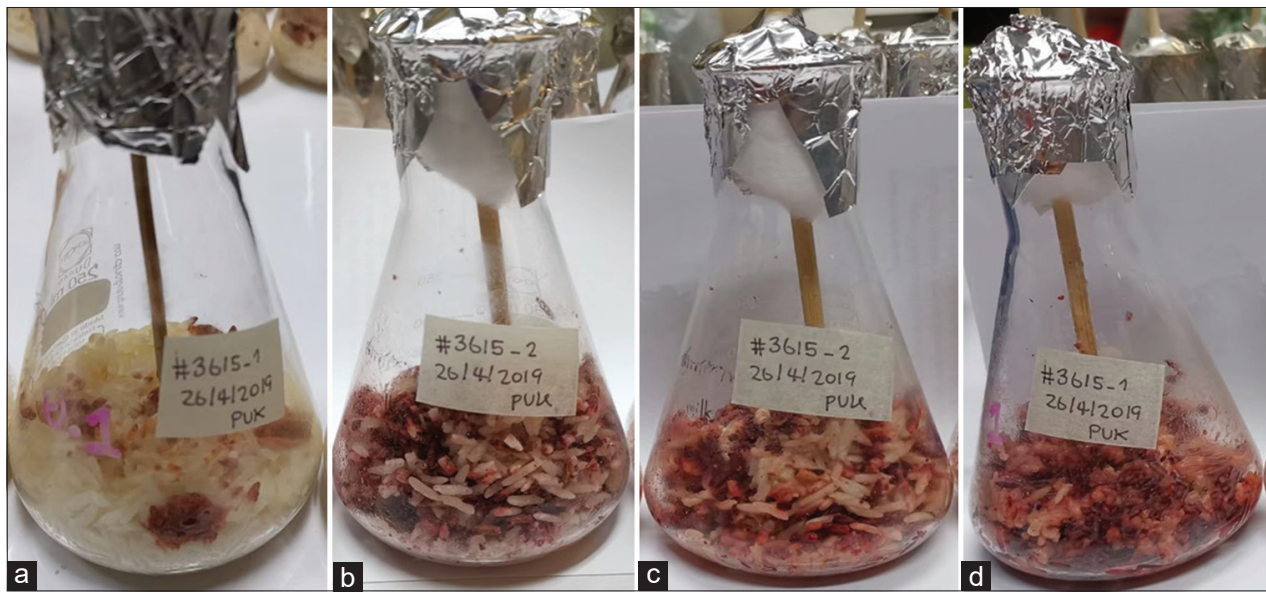

Fig. 2: The production of red pigment of Monascus purpureus TISTR3515 under solid-state fermentation; (a) 3 days, (b) 5 days, (c) 7 days and (d) 10 days

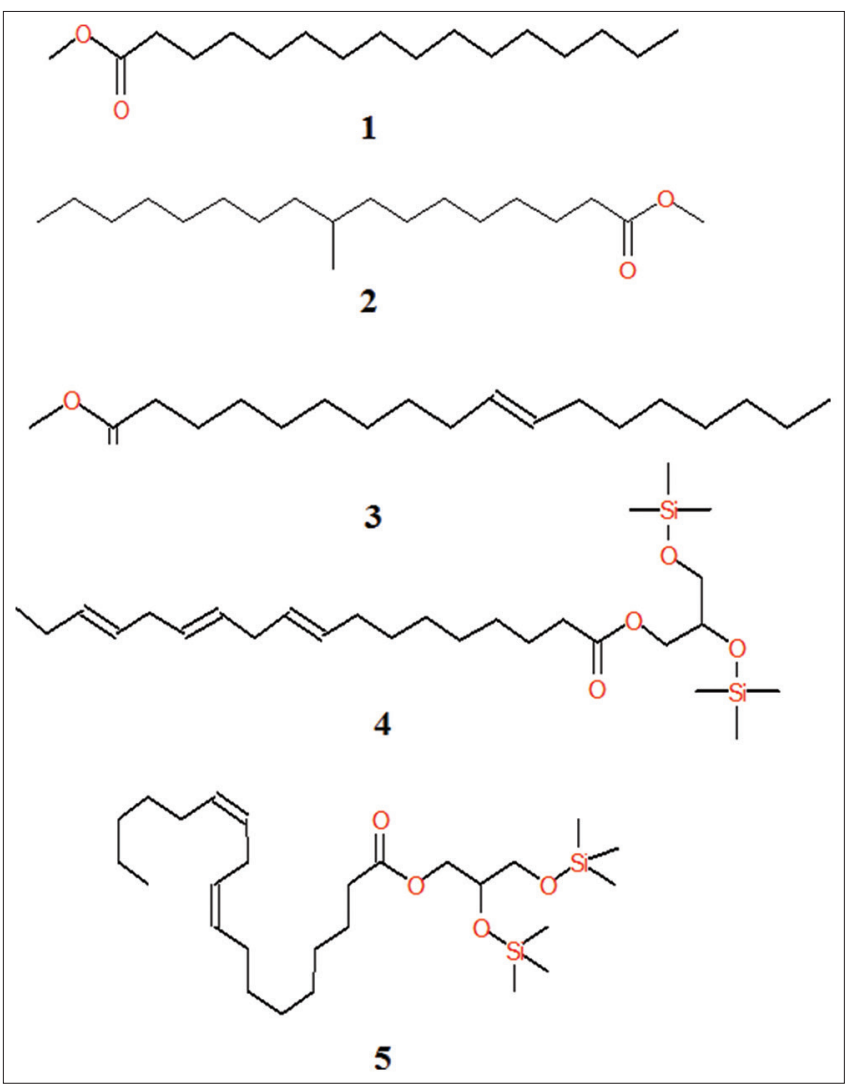

Fig. 3: The chemical structure of red pigment of Monascus purpureus TISTR3515 under solid-state fermentation using Pathum thani rice1 as carbon source. (1) Hexadecanoic acid, methyl ester, (2) hexadecanoic acid, methyl ester, (3) 10-Octadecenoic acid, methyl ester, (4) 9,12,15-0ctadecatrienoic acid,2,3-bis [(trimethylsilyl) oxy]propyl ester, (Z,Z,Z)-, (5) 1-Monolinoleoylglycerol trimethylsilyl ether

Other studies also reported that Monascus fermented rice, soybean, and adlay possess DPPH radical scavenging activity [22].

\section{GC-MS analysis of crude extracts of red pigment}

The crude extracts of red pigment of M. purpureus TISTR3615 under solid-state fermentation were determined by GC-MS. The active principles with their retention time (RT), molecular formula, molecular weight, concentration (peak area \%), and
Table 1: Antioxidant activity of red pigment of Monascus purpureus TISTR3615 under solid-state fermentation using Pathumthani rice1 as a carbon source

\begin{tabular}{|c|c|c|c|c|}
\hline \multirow[t]{2}{*}{ Sample } & \multicolumn{4}{|c|}{ Antioxidant activity } \\
\hline & DPPH $^{b}$ & ABTS $^{c}$ & FRAP $^{d}$ & TPC $^{e}$ \\
\hline SSFa & $97.80 \pm 1.51$ & $68.64 \pm 0.46$ & $0.32 \pm 0.021$ & $164.78 \pm 2.82$ \\
\hline Vit. $\mathrm{C}^{\mathrm{f}}$ & $93.54 \pm 2.16$ & $96.70 \pm 0.01$ & $1.14 \pm 0.00$ & - \\
\hline
\end{tabular}

sample, ${ }^{\mathrm{e}} \mu \mathrm{g}$ of GAE/g of sample, ${ }^{\mathrm{f}}$ Vitamin C

Table 2: The chemical analysis of red pigment from Monascus purpureus TISTR3615

\begin{tabular}{llll}
\hline RT $^{\mathbf{a}}$ & $\begin{array}{l}\text { Molecular } \\
\text { weight }^{\mathbf{b}}\end{array}$ & Compounds & Formula \\
\hline 13.437 & 270 & $\begin{array}{l}\text { Hexadecanoic acid, methyl } \\
\text { ester }\end{array}$ & $\mathrm{C}_{17} \mathrm{H}_{34} \mathrm{O}_{2}$ \\
16.097 & 298 & $\begin{array}{l}\text { Heptadecanoic acid, } \\
\text { 9-methyl-, methyl ester }\end{array}$ & $\mathrm{C}_{19} \mathrm{H}_{38} \mathrm{O}_{2}$ \\
15.764 & 296 & $\begin{array}{l}\text { 10-Octadecenoic acid, methyl } \\
\text { ester }\end{array}$ & $\mathrm{C}_{19} \mathrm{H}_{36} \mathrm{O}_{2}$ \\
22.143 & 496 & $\begin{array}{l}\text { 9,12,15-Octadecatrienoic } \\
\text { acid, 2,3 bis [(trimethylsilyl) } \\
\text { oxy]propyl ester, (Z,Z,Z)- }\end{array}$ & $\mathrm{C}_{27} \mathrm{H}_{52} \mathrm{O}_{4} \mathrm{Si}_{2}$ \\
& & $\begin{array}{l}\text { 1-Monolinoleoylglycerol } \\
\text { trimethylsilyl ether }\end{array}$ & $\mathrm{C}_{27} \mathrm{H}_{54} \mathrm{O}_{4} \mathrm{Si}_{2}$ \\
26.355 & 498 & & \\
\hline aRetention time, ${ }^{\text {bMolecular weight }}$
\end{tabular}

the chemical structure were analyzed. Table 2 shows that the components present in the ethyl acetate extract as identified by GCMS and Fig. 3 shows the chemical structure of red pigments. These compounds, 9,12,15-Octadecatrienoic acid,2,3-bis [(trimethylsilyl) oxy]propyl ester, $(\mathrm{Z}, \mathrm{Z}, \mathrm{Z})$, were the first report that produced by M. purpureus and played important role for biologically activity such as anti-oxidant, anti-diabetic, and anti-inflammatory [23], whereas 1-Monolinoleoylglycerol trimethylsilyl ether are being used for antimicrobial, anti-oxidant, anti-inflammatory, anti-arthritic, antiasthma, and diuretic [24].

\section{CONCLUSION}

From the above study, the results revealed that the crude extracts of red pigment of M. purpureus TISTR3615 under solid-state fermentation (Pathumthani1 rice) were potential of antioxidant activity and it 
possible apply to use as a natural coloring agent and natural for food additive as well as cosmetic application in the future.

\section{ACKNOWLEDGMENTS}

The authors wish to thank Rajamangala University of Technology Thanyaburi and Thai Traditional Medicine College, RMUTT, for financial supported.

\section{DECLARATION OF INTEREST}

This manuscript has not been published and is not under consideration for publication elsewhere. We have no conflicts of interest to disclose.

\section{REFERENCES}

1. Al-Obaidi RS, Sahib DH. Determination of antioxidants activity in tea extract. Am J Biochem Biotechnol 2015;5:49-52.

2. Joshi VK, Anjubala AD, Bhushan S. Microbial pigments. Indian J Biotechnol 2003;2:362-9.

3. Prescott SC, Dunn CC. Industrial Microbiology. $3^{\text {rd }}$ ed. New York: McGraw Hill; 1959.

4. Panesar R, Kaur S, Panesar PS. Production of microbial pigments utilizing agro-industrial waste: A review. J Food Sci 2015;1:70-6.

5. Campoy S, Rumbero A, Martin JF, Liras P. Characterization of a hyperpigmenting mutant of Monascus purpureus IB1: Identification of two novel pigment chemical structures. Appl Microbiol Biotechnol 2006;70:488-96.

6. Zhou B, Wang J, Pu Y, Zhu M, Liu S, Liang S. Optimization of culture medium for yellow pigments production with Monascus anka mutant using response surface methodology. Eur Food Res Technol 2009;228:895-901.

7. Fabre CE, Santerre AL, Loret MD, Baberian R, Parailleux A, Goma G. Production and food application of the red pigments of Monascus ruber. J Food Sci 1993;58:1099-103.

8. Lin YL, Wang TH, Lee MH, Su NW. Biologically active components and nutraceuticals in the Monascus fermented rice: A review. Appl Microbiol Biotechnol 2008;7795:965-73.

9. Kumar A, Verma U, Sharma H. Antibacterial activity Monascus purpureus (red pigment) isolated from rice malt. Asian J Biol Life Sci 2012;1:252-5.

10. Rajasekaran A, Kalaivani M. Hypolipidemic and antioxidant activity of aqueous extract of Monascus purpureus fermented Indian rice in high cholesterol diet fed rats. Turk J Med Sci 2011;41:25-32.
11. Dhale MA, Divakar S, Kumar SU, Vijayalakshmi G. Isolation and characterization of dihydromonacolin-MV from Monascus purpureus for antioxidant properties. Appl Microbiol Biotechnol 2007;73:1197-202.

12. Nimnoi P, Pongsilp N, Lumyoung S. Utilization of agro-industrial products for increasing red pigment production of Monascus purpureus AHK12. Chiang Mai J Sci 2015;42:331-8.

13. Kodama DH, Gonçalves A, Lajolo FM, Genovese MI. Flavonoids, total phenolic and antioxidant capacity: Comparison between commercial green tea preparations. Food Sci Technol 2010;30:1077-82.

14. Surachai T, Khemjira J, Warachate K. Total antioxidant capacity of Thai herbal teas by the ferric reducing antioxidant power. Appl Mech Mater 2019;886:46-51.

15. Valgas C, Souza SM, Smânia EF, Smânia AJ. Screening methods to determine antibacterial activity of natural products. Braz J Microbiol 2007:38:369-79.

16. Chairote E, Chairote G, Lumyoung S, Red yeast rice prepared from Thai glutinous rice and the antioxidant activities. Chiang Mai J Sci 2009;36:42-9.

17. Silbir S, Goksungur Y. Natural red pigment production by Monascus purpureus in submerged fermentation systems using a food industry waste; brewer's spent grain. Foods 2019;8:1-14.

18. Saithong P, Chitisankul WT, Nitipan S. Comparative study of red yeast rice with high monacolin $\mathrm{K}$, low citrinin concentration and pigments in white rice and brown rice. Czech J Food Sci 2019;37:75-80.

19. Srianta, I Nugerahani I, Kusumawati N, Suryatanijaya E, Subianto C. Therapeutic antioxidant activity of Monascus fermnted durian seed: A potential functional food ingredient. Int J Nutr Public Health 2014;7:53-9.

20. Srianta I, Zubaidah E, Estiasih T, Iuchi Y, Harijono H, Yamada M. Antioxidant activity of pigments derived from Monascus purpureus fermented rice, corn, and sorghum. Int Food Res J 2017;24:1186-91

21. Pengnoi P, Mahawan R, Khanongnuch C, Lumyoung S. Antioxidant properties and production of monacolin $\mathrm{K}$, citrinin, and red pigments during solid-state fermentation of purple rice (Oryzae sativa) varieties by Monascus purpureus. Czech J Food Sci 2017;35:32-9.

22. Lee YL, Yang JH, Mau JL, Antioxidant properties of water extracts from Monascus fermented soybeans. J Food Biochem 2008;106:1128-37.

23. Rajendran P, Bharnthidasan R, Sureshkumar K Analysis of phytocomponent in raw and treated sugarcane juice. Int $\mathrm{J}$ Curr Microbiol Appl 2017;6:51-61.

24. Parthipan B, Suky MG, Mohan VR. GC-MS analysis of phytocomponents in Pleiospermium alatum (Wall. Ex Wight and Arn.) Swingle, (Rutaceae). J Pharmacogn Phytochem 2015;4:216-22. 